read Jaspers in the original German text. This made me smile, as I had an almost identical experience as a senior house officer in neurology in Dublin. At the time, I was working for a prominent neurologist, Hugh Staunton - who, by the by, went to the same school as Joyce. During a morning ward round I was minded by Dr Staunton that the reason I had failed to spot a neurological sign in a man with von Recklinghausen's disease was that I had not read the author of this eponymous condition in the original German text. Somewhat belittled at the time, I now know I am in esteemed company.
1 Tyrer P. Ten books. Br J Psychiatry 2009; 195: 273-5

2 Damasio A. Looking for Spinoza: Joy, Sorrow, and the Feeling Brain. Vintage, 2004

3 Walker A, Fitzgerald M. Unstoppable Brilliance: Irish Geniuses and Asperger's Syndrome. Liberties Press, 2006.

Paul J. Whelan, Central and North West London NHS Foundation Trust, Nort Westminster Older Adults Community Mental Health Team, Latimer House, 40 Hanson Street, London W1 W6UL, UK. Email: paul.whelan@nhs.net

doi: 10.1192/bjp.195.6.555a psychiatry in pictures

\title{
The Insect Twins (2009)
}

Lucinda Richards

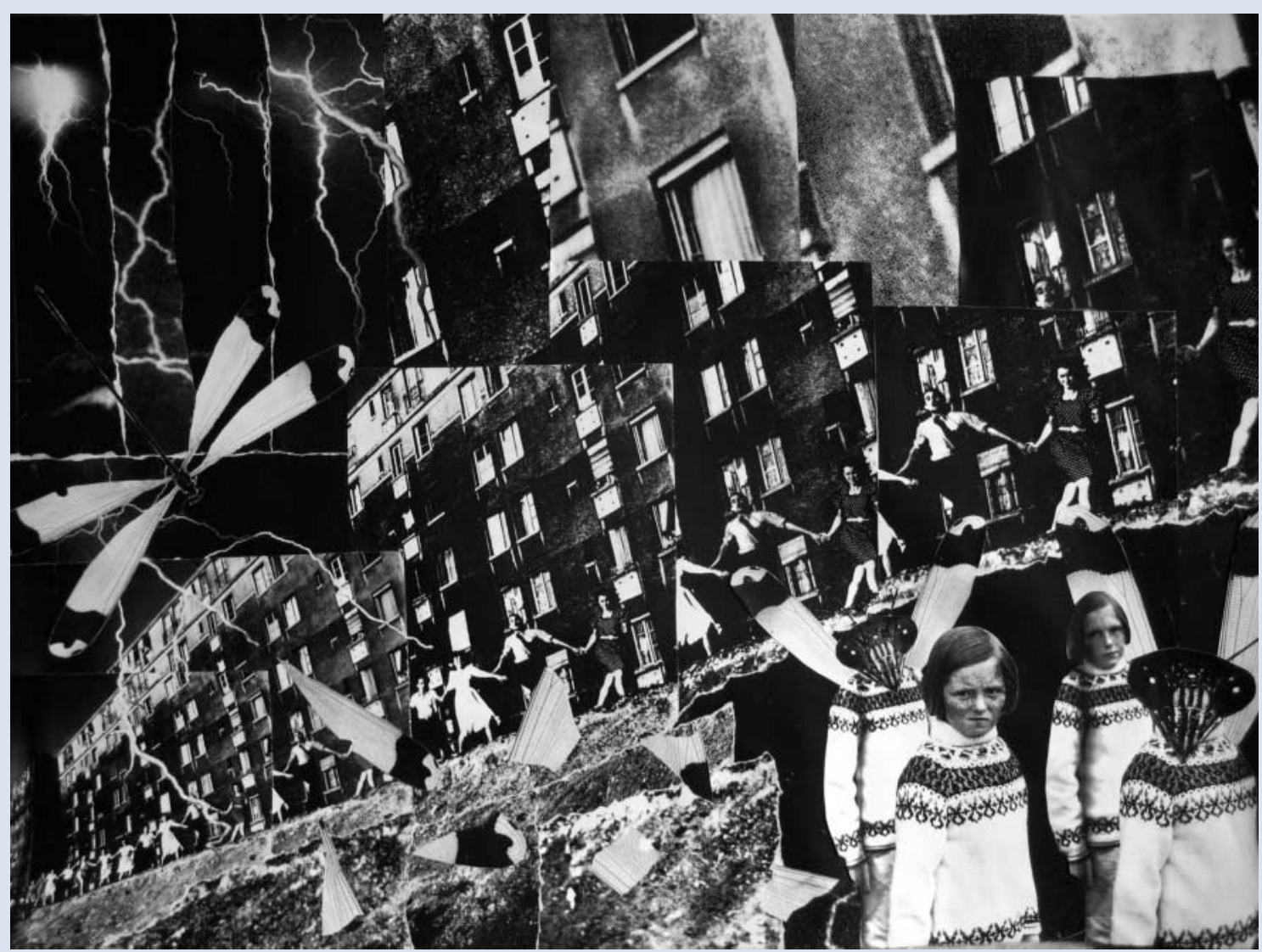

Lucinda Richards is a foundation trainee (year 2) at King's College Hospital, London. This work portrays the world as seen by patients with delirium that she has cared for.

'I wanted to consider how patients with delirium experience a sudden change in how they perceive the world around them. I am especially interested in how objects or people that normally provoke a neutral or positive reaction can become distorted into something terrifying. The terror and hallucinations that can occur in delirium are represented by the larger-than-life insects and the transformation of the seemingly innocent children into something disturbing and sinister. In addition, the juxtaposition of the apparently joyful chain of people with the dark, oppressive flats in the background has the effect of making the expression of joy seem false and fragile. The lightning strike, forming cracks in the architecture represents the destruction of normal brain architecture. The disturbances in temporal and spatial orientation are portrayed by the images of both night and day, and the distortion in the size of the architecture and insects.'

Edited by Allan Beveridge. 